\title{
Studi Komparasi Komposter Berbasis Masyarakat
}

\author{
NATASYA HASNA AFIFAH ${ }^{1}$, IWAN JUWANA ${ }^{1}$, MOHAMAD SATORI ${ }^{2}$ \\ 1. Jurusan Teknik Lingkungan, Fakultas Teknik Sipil dan Perencanaan, \\ Institut Teknologi Nasional, Bandung \\ 2. Jurusan Teknik Industri, Fakultas Teknik, Universitas Islam Bandung, \\ Bandung \\ Email : hasnatasya69@gmail.com
}

\begin{abstract}
ABSTRAK
Sampah organik merupakan sampah dominan di Bank sampah Sahdu, maka perlu pengolahan untuk mengurangi timbulan sampah organik di TPA. Penelitian ini membandingkan 3 jenis komposter aerob di Bank sampah Sahdu yaitu bata terawang, drum dan takakura. Jenis sampah yang digunakan adalah sampah organik campuran (sisa makanan dan sampah halaman). Kapasitas komposter bata terawang, drum dan takakura dapat menampung sampah per harinya dari 456, 210 dan 20 sumber. Kinerja komposter bata terawang, drum dan takakura dalam mengolah sampah organik menjadi kompos adalah 53,45\%, 48,27\% dan 56,01\%. Kualitas kompos yang dihasilkan seluruh komposter memenuhi baku mutu, kecuali parameter pH kompos dari hasil komposter drum tidak memenuhi baku mutu.
\end{abstract}

Kata kunci: sampah organik, bank sampah, komposter aerobik.

\section{ABSTRACT}

Organic waste is the most dominant waste produced, thus the reduction of this type of waste will reduce waste entering the landfill. This research aims were to compare the performance of 3 types of aerobic composters in Waste bank Sahdu which are brick overlay, drum and takakura. The wastes used in this research is mixed organic waste (food waste and yard waste). The capacity of brick overlay, drum and takakura are able to treat waste per day from 456, 210 and 20 households respectively. As related to their performance, the bric overlay, drum and takakura are able to treat $53,45 \%, 48,27 \%$ and $56,01 \%$ of organic waste into compost, respectively. The compost quality that produced by all composter has met the standard quality, except $\mathrm{pH}$ parameters from the composter drum.

Keyword: organic waste, waste bank, aerobic composter. 


\section{PENDAhULUAN}

Kebijakan dan program pengurangan sampah sebagaimana amanat undang-undang No.18 Tahun 2008, saat ini masih menjadi permasalahan di hampir semua daerah/wilayah di Indonesia. Berdasarkan data dari Kementerian Lingkungan Hidup dan Kehutanan (KLHK) tahun 2016 , secara nasional rata-rata sampah tertangani $67 \%$ dan yang tidak tertangani $33 \%$, sedangkan persentase untuk pengurangan sampah dari total sampah yang tertangani baru mencapai $16 \%$, sedangkan sisanya yaitu $84 \%$ masuk ke TPA.

Selain itu menurut data dan informasi yang dikeluarkan Kementerian Lingkungan Hidup dan Kehutanan (KLHK) dalam acara National Action Plan on Marine Plastic Debris tahun 2017 bahwa rata-rata timbulan sampah yang dihasilkan di Indonesia setiap tahunnya sebesar 64 juta ton sampah, dengan persentase berdasarkan komposisinya sampah organik $60 \%$ dan sampah anorganik $40 \%$.

Kondisi ini dapat diantisipasi oleh pola penanganan yang dimulai dari sumber sampah dengan menerapkan sistem 3R sehingga kebijakan pengurangan sampah dapat terealisasi. Salah satu upaya 3R di sumber sampah adalah dengan melakukan pengomposan. Pengomposan sendiri merupakan proses penguraian sampah organik menjadi kompos, teknologi atau alat yang digunakan untuk pengomposan disebut komposter.

Lokasi penelitian di Bank sampah Sahdu yang terletak di Kabupaten Bandung Barat. Bank sampah Sahdu merupakan bank sampah yang menerima sampah organik dan anorganik untuk diolah, dimana pengolahan sampah organiknya menggunakan komposter. Penelitian ini menggunakan 3 jenis komposter yang berbeda yaitu bata terawang, drum dan takakura. Maksud dari penelitian ini adalah membandingka performa kinerja komposter yang tersedia di Bank sampah Sahdu, dengan tujuan untuk mengetahui pemanfaatan dan penempatan teknologi yang tepat guna, serta mengidentifikasi penggunaan teknologi untuk meningkatkan kualitas dan manfaat kompos yang dihasilkan.

\section{METODOLOGI}

\subsection{Pengumpulan Data}

Pengumpulan data dalam penelitian ini terbagi menjadi dua yaitu data primer dan data sekunder.

\subsubsection{Data Primer}

Data primer merupakan data yang dikumpulkan langsung di tempat objek penelitian (Sugiyono, 2009). Pengumpulan data primer dalam penelitian ini digunakan untuk menunjang perhitungan kapasitas dan kinerja komposter. Komposter yang digunakan adalah bata terawang, drum dan takakura. Jenis sampah yang digunakan adalah sampah campuran yang terdiri dari sampah sisa makanan dan sampah halaman.

Data yang diperlukan untuk mengetahui kapasitas komposter adalah jumlah sampah yang masuk ke dalam komposter, data ini diperoleh dari pengukuran berat sampah. Selain itu data lain yang diperlukan adalah data berat sampah di lokasi penelitian, diperoleh dari hasil pengukuran dan perhitungan rata-rata berat sampah yang dihasilkan di lokasi penelitian selama 7 hari berturut-turut.

Data primer yang diperlukan untuk mengetahui kinerja komposter adalah berat kompos halus, data ini diperoleh dari pengukuran berat kompos yang dihasilkan dari masing-masing komposter serta data jumlah sampah yang masuk ke dalam komposter. 


\subsubsection{Data Sekunder}

Data sekunder adalah data yang telah tersedia dari hasil penelitian atau observasi sebelumnya (Sugiyono, 2009). Data sekunder yang diperlukan dalam penelitian ini adalah data lokasi penelitian dan jumlah penduduk yang diperoleh dari kelurahan dan pengurus RT setempat, data tersebut diperlukan untuk menunjang keberlangsungan penelitian. Selain itu, data sekunder lain yang diperlukan adalah kualitas kompos yang dihasilkan di Laboratorium Kimia Tanah Universitas Padjajaran. Parameter yang diuji antara lain tingkat keasaman $(\mathrm{pH})$, kadar air, rasio $\mathrm{C} / \mathrm{N}$, tembaga $(\mathrm{Cu})$ dan seng $(\mathrm{Zn})$. Pengukuran $\mathrm{pH}$ menggunakan alat ukur $\mathrm{pH}$ meter. Pengukuran kadar air menggunakan metode pengeringan. Pengukuran rasio $\mathrm{C} / \mathrm{N}$ terbagi menjadi 2 tahap yaitu tahap pengukuran C-organik menggunakan metode Walkley \& Black dan tahap pengukuran $\mathrm{N}$ total menggunakan metode Kjeldahl. Pengukuran unsur mikro tanaman yaitu tembaga $(\mathrm{Cu})$ dan seng $(\mathrm{Zn})$ menggunakan metode spektrofotometri.

\subsection{Pengomposan}

Pengomposan oleh komposter aerob dilakukan dalam kurun waktu 4-6 minggu. Perlakuan yang dilakukan selama proses pengomposan adalah penambahan larutan aktivator, pengadukan dan pengecekkan suhu sebanyak 2 hari sekali.

Penambahan larutan aktivator dilakukan untuk mempercepat penguraian bahan organik oleh mikroorganisme. Penambahan larutan dilakukan hingga mengenai semua permukaan bahan secara merata. Penambahan larutan diusahakan tidak membuat bahan terlalu lembab karena akan menghambat pertumbuhan mikroorganisme, dimana rongga udara akan terisi oleh molekul air hal ini dapat merubah proses menjadi anaerobik, namun apabila kekurangan dapat mengakibatkan berkurangnya jumlah mikroorganisme pengurai (Dharmasetiawan, 2006). Larutan aktivator yang diberikan untuk setiap komposter merupakan campuran air, larutan EM4 dan larutan gula.

Pengadukan merupakan salah satu upaya aerasi atau penyediaan oksigen agar dapat terjadi proses penguraian dam menghomogenkan distribusi nutrisi (Tchobanoglous et al, 1993). Pengadukan juga sangat diperlukan apabila bahan organik memiliki kelembaban yang tinggi. Cara pengadukan terhadap komposter bata terawang dan drum adalah dengan mengeluarkan sampah melalui pintu bawah komposter, lalu dimasukkan kembali ke dalam komposter. Sedangkan pengadukan terhadap takakura dilakukan dengan cara mengaduk kompos menggunakan sekop kecil.

Untuk memantau berjalan atau tidaknya proses pengomposan yaitu dengan melakukan pengecekkan suhu. Pengukuran suhu dengan termometer dilakukan di 5 titik yaitu di 4 ujung sisi dan tengah, pengukuran di 5 titik bertujuan pengukuran suhu lebih akurat. Pengecekkan suhu juga dilakukan ketika kompos sudah matang.

\subsection{Perhitungan Kapasitas Komposter}

Kapasitas komposter diperoleh dari mengukur jumlah sampah yang terkumpul dan masuk ke dalam komposter. Kapasitas komposter dilihat dari ketersediaan komposter menampung sampah, maka dari itu dapat diketahui jumlah sumber sampahnya dari rumus perhitungan :

Jumlah Sumber $=\frac{\text { Berat Sampah yang Masuk Komposter }}{\text { Berat Sampah yang Dihasilkan }}$

\subsection{Perhitungan Kinerja Komposter}

Kinerja komposter dilihat dari kemampuan komposter dalam mengolah sampah organik menjadi kompos yang layak digunakan (kompos halus). Persentase kinerja masing-masing komposter diperoleh dari rumus perhitungan :

Persentase Kompos Halus $=\frac{\text { Berat Kompos Halus }}{\text { Berat Sampah yang Masuk Komposter }} \times 100 \%$ 
Selain itu kinerja komposter dengan mengobservasi temuan atau kejadian yang terjadi selama proses pengomposan. Temuan ini dapat dikategorikan dalam menguntungkan atau merugikan.

\section{HASIL DAN PEMBAHASAN}

\subsection{Pengomposan}

Pengomposan adalah suatu proses perubahan bahan-bahan organik yang dapat diurai menjadi bahan yang stabil dan tidak berbau (kompos) oleh mikroorganisme (Soma, 2010). Bahan organik yang digunakan dalam penelitian ini adalah sampah organik domestik yang terdiri dari sampah sisa makanan dan sampah halaman.

Pengomposan berlangsung selama 45 hari, sudah termasuk proses pengeringan dan pemanenan kompos. Selama proses pengomposan masing-masing komposter diberi perlakuan yang sama yaitu pengadukan, pemberian larutan aktivator dan pengamatan suhu.

Pengukuran suhu dilakukan guna memantau perkembangan mikroorganisme dalam mengurai bahan organik. Grafik fluktuasi suhu selama proses pengomposan dapat dilihat pada Gambar 3.1.

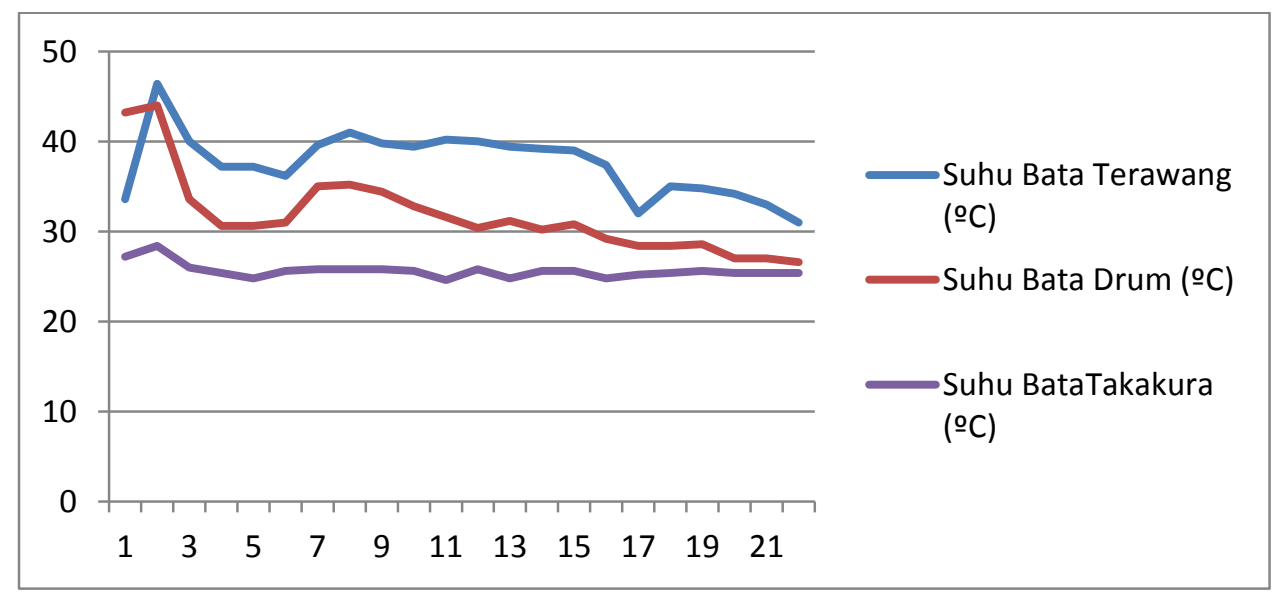

Gambar 3.1 Grafik Fluktuasi Suhu

Berdasarkan grafik pada Gambar 3.1 pengomposan yang dilakukan sejalan dengan literatur, dimana awal pengomposan adalah fase mesofilik dilihat di hari ke 2 suhu pada ke empat komposter berada di rentang $25^{\circ} \mathrm{C}-45^{\circ} \mathrm{C}$. Setelah hari ke 2 terjadi kenaikan suhu yang menandakan pemindahan dari fase mesofilik menjadi fase termofilik. Suhu tinggi dalam proses pengomposan berfungsi untuk mematikan gulma dan mikroorganisme patogen. Setelah melewati fase termofilik, suhu bahan organik relatif terus menurun yang berarti masuk fase pendinginan. Fase pendinginan menandakan penguraian bahan organik yang lebih sederhana.

Komposter bata terawang memiliki rata-rata suhu paling tinggi, sedangkan takakura memiliki suhu terendah yaitu berada di rentang $24^{\circ} \mathrm{C}-27^{\circ} \mathrm{C}$. Hal ini dipengaruhi oleh volume komposter, dimana semakin luas volume komposter maka jumlah bahan organik yang harus diurai semakin banyak dan energi berupa panas yang dilepas juga akan semakin besar.

\subsection{Kapasitas Komposter}

Kapasitas komposter merupakan besaran yang dapat ditampung oleh komposter dalam melakukan proses pengomposan. Perhitungan kapasitas komposter dimulai dengan mengukur berat sampah yang masuk ke masing-masing komposter selama 7 hari berturutturut. Data berat sampah yang masuk ke dalam komposter dapat dilihat pada Tabel 3.1. 
Tabel 3.1 Berat Sampah yang Masuk ke dalam Komposter

\begin{tabular}{|c|c|c|c|c|}
\hline \multirow{2}{*}{ No } & \multirow{2}{*}{ Hari Ke- } & \multicolumn{3}{|c|}{ Berat Sampah yang Masuk (kg) $\left(^{*}\right)$} \\
\hline & & Bata Terawang & Drum & Takakura \\
\hline 1 & 1 & 5,97 & 9,02 & 0,77 \\
\hline 2 & 2 & 15,34 & 7,11 & 1,29 \\
\hline 3 & 3 & 20,52 & 8,85 & 0,72 \\
\hline 4 & 4 & 7,79 & 16,26 & 2,79 \\
\hline 5 & 5 & 26,58 & 7,7 & - \\
\hline 6 & 6 & 10,27 & 10,77 & - \\
\hline 7 & 7 & 43,25 & - & - \\
\hline \multicolumn{2}{|c|}{ Total $(* *)$} & 129,72 & 59,71 & 5,57 \\
\hline
\end{tabular}

Data berat sampah yang dihasilkan di lokasi penelitian diperoleh dari perhitungan hasil bagi total berat sampah organik yang dihasilkan dengan total penduduk. Rata-rata berat sampah yang dihasilkan selama 7 hari adalah 0,28 kg/orang/hari. Kapasitas komposter dapat dengan menentukan jumlah sumber sampah yang dapat ditampung oleh masing-masing komposter. Untuk memperolehnya dilakukan perhitungan.

Contoh perhitungan jumlah sumber komposter bata terawang (April 2018):

\begin{tabular}{|c|c|}
\hline \multicolumn{2}{|c|}{$\begin{array}{l}\text { Berat sampah yang masuk }=129,72 \mathrm{~kg} \\
\text { Timbulan sampah }=0,28 \mathrm{~kg} / \mathrm{org} / \mathrm{hari}\end{array}$} \\
\hline Jumlah sumber & $=\frac{\text { Berat sampah yang masuk komposter }}{\text { Berat sampah yang dihasilkan }}$ \\
\hline & $=\frac{129,72 \mathrm{~kg}}{0,28 \mathrm{~kg} / \mathrm{org} / \text { hari }}$ \\
\hline & $=456$ orang \\
\hline
\end{tabular}

Rekapitulasi kapasitas masing-masing komposter yang sudah dilakukan perhitungan dapat dilihat pada Tabel $\mathbf{3 . 2}$.

Tabel 3.2 Rekapitulasi Kapasitas Komposter

\begin{tabular}{lc}
\hline \multicolumn{1}{c}{ Komposter } & Jumlah Sumber Sampah (orang) \\
\hline Bata terawang & 456 \\
\hline Drum & 210 \\
\hline Takakura & 20 \\
\hline (Sumber: Hasil Perhitungan, 2018) &
\end{tabular}

Data kapasitas komposter dalam menampung sampah seperti pada Tabel 3.2. menunjukkan bahwa komposter bata terawang dan drum dapat menampung sampah dari sumber dengan jumlah skala RT/RW per harinya, maka dari itu bata terawang dan drum termasuk ke dalam komposter komunal atau komposter yang lebih cocok digunakan bersama-sama. Sedangkan takakura merupakan komposter yang dapat menampung sampah dengan skala lebih kecil yaitu 20 orang per harinya, maka dari itu takakura termasuk ke dalam komposter individu atau komposter yang lebih cocok digunakan per rumah. 


\subsection{Kinerja Komposter}

Komposter bekerja mengolah sampah organik campuran menjadi kompos. Hasil penelitian menunjukkan bahwa sampah organik yang masuk ke seluruh komposter mengasilkan kompos halus, kompos kasar dan khusus komposter drum mengeluarkan air lindi. Secara garis besar flowchart sumber dan hasil dari proses pengomposan dapat dilihat pada Gambar 3.2.

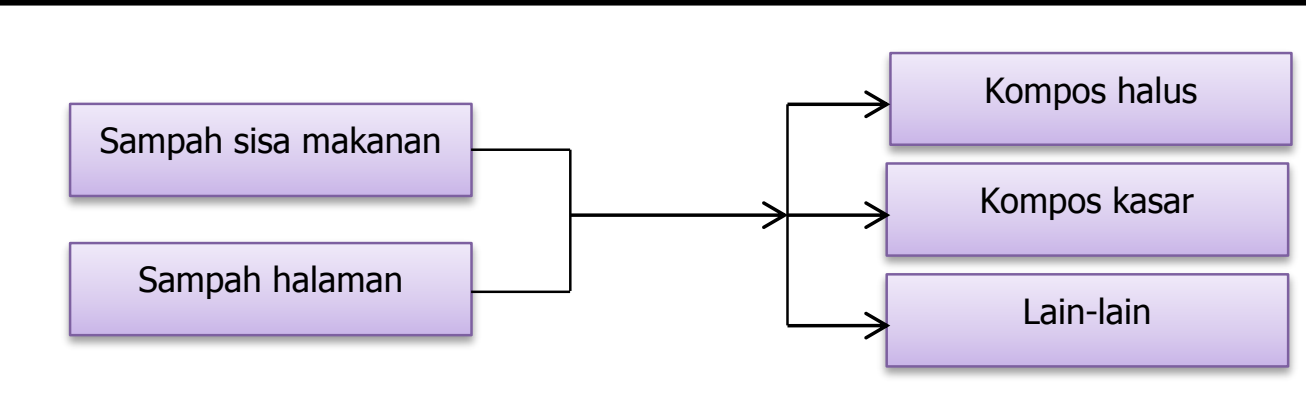

Gambar 3.2 Flowchart Hasil Pengomposan

Persentase hasil pengomposan dari ke empat komposter diperoleh dari hasil perhitungan, dengan contoh perhitungan dari komposter bata terawang sebagai berikut :

Contoh perhitungan persentase kompos halus komposter bata terawang (April 2018):

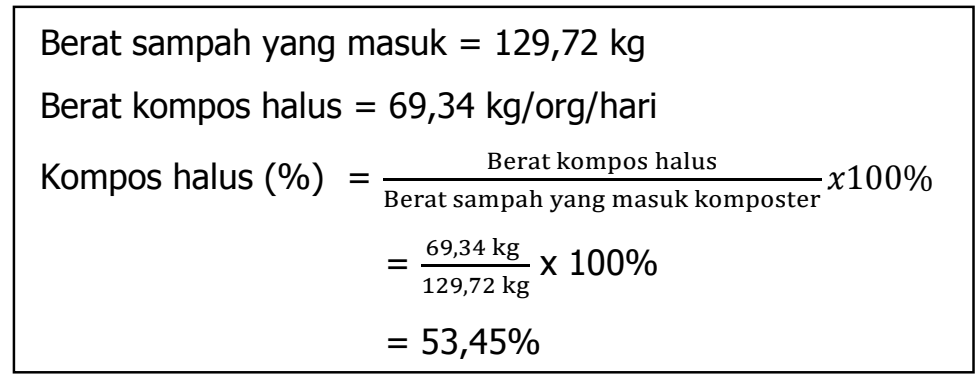

Rekapitulasi hasil perhitungan persentase kompos halus, kompos kasar dan lain-lain dapat dilihat pada Tabel 3.3.

Tabel 3.3 Persentase Hasil Pengomposan

\begin{tabular}{cccc}
\hline \multirow{2}{*}{ Komposter } & \multicolumn{3}{c}{ Persentase (\%) } \\
\cline { 2 - 4 } & Kompos Halus & Kompos Kasar & Lain-Lain \\
\hline Bata terawang & 53,45 & 44,31 & 2,24 \\
\hline Drum & 48,27 & 45,03 & 6,70 \\
\hline Takakura & 56,01 & 33,75 & 10,24 \\
\hline
\end{tabular}

(Sumber: Hasil Perhitungan, 2018)

Kompos halus adalah kompos yang berhasil lolos dari ayakan dengan lubang saringan 0,1 $\mathrm{cm} \times 0,1 \mathrm{~cm}$. Kompos halus merupakan hasil kompos yang dapat langsung digunakan. Kompos kasar adalah kompos yang tidak lolos saringan. Kompos kasar yang dimaksud adalah seperti kulit buah-buahan, dedaunan, ranting dan bahan yang berukuran besar lainnya. Persentase lain-lain yang dimaksud adalah perubahan sampah menjadi ammonia $\left(\mathrm{NH}_{3}{ }^{+}\right)$, karbon dioksida $\left(\mathrm{CO}_{2}\right)$, uap air dan panas akibat penguraian oleh mikroorganisme, hal ini juga memungkinkan akan mengurangi berat sampah (Yulianto, 2009).

Kinerja komposter dapat dihitung dari kemampuannya dalam menghasilkan kompos dari jumlah bahan organik yang masuk ke dalam komposter. Takakura merupakan komposter 
yang memiliki kinerja paling besar dibandingkan komposter lainnya, hal ini dikarenakan jumlah sampah halaman yang harus diurai paling sedikit dibandingkan komposter lainnya. Mengingat sampah sisa makanan lebih mudah diurai dan membusuk dibandingkan sampah halaman.

Kinerja dapat lebih di optimalkan dengan cara mencacah sampah sampai ukuran luasannya lebih kecil, hal ini bertujuan untuk mengurangi bahan mikroorganisme dalam menguraikan bahan organik dan mengurangi kompos kasar yang dihasilkan.

\subsection{Kualitas Kompos}

Kualitas kompos yang dihasilkan mempengaruhi kelayakan kompos untuk digunakan konsumen dan mencegah pencemaran lingkungan. Acuan kualitas kompos adalah Standar Nasional Indonesia (SNI) 19-7030-2004 tentang Spesifikasi Kompos dari Sampah Organik Domestik. Parameter kualitas kompos yang di uji antara lain :

\section{a. Suhu}

Suhu merupakan salah satu parameter yang menjadi indikator kematangan suatu kompos. Menurut SNI 19-7030-2004 suhu yang diperbolehkan untuk kompos yang layak digunakan adalah maksimum sesuai dengan suhu air tanah yang dapat diserap oleh akar tumbuhan yaitu $\leq 30^{\circ} \mathrm{C}$. Pengukuran suhu juga dilakukan langsung di lokasi penelitian menggunakan termometer. Rekapitulasi nilai suhu dapat dilihat pada Tabel 3.4.

Tabel 3.4 Nilai Suhu Kompos

\begin{tabular}{|c|c|c|c|c|c|}
\hline \multirow{2}{*}{ Komposter } & \multirow{2}{*}{ Satuan } & \multirow{2}{*}{ Suhu $(*)$} & \multicolumn{2}{|c|}{ Baku Mutu (**) } & \multirow{2}{*}{$\begin{array}{c}\text { Kesesuaian } \\
(* * *)\end{array}$} \\
\hline & & & Min & Maks & \\
\hline Bata Terawang & \multirow{3}{*}{${ }^{\circ} \mathrm{C}$} & 29 & \multirow{3}{*}{-} & \multirow{3}{*}{30} & Memenuhi \\
\hline Drum & & 27 & & & Memenuhi \\
\hline Takakura & & 24 & & & Memenuhi \\
\hline
\end{tabular}

Hasil pengukuran suhu menunjukkan bahwa kompos hasil komposter bata terawang memiliki nilai tertinggi selanjutnya drum dan takakura, nilai suhu kompos dari ketiga komposter memenuhi baku mutu yang ada. Nilai suhu dapat mempengaruhi kadar air suatu kompos. Selain itu nilai suhu kompos yang tinggi menunjukkan bahwa energi panas yang dihasilkan tinggi atau sama dengan jumlah bahan organik yang diurai semakin banyak. Hal ini sesuai dengan kondisi di lokasi penelitian bahwa jumlah sampah yang masuk ke dalam komposter tertinggi adalah bata terawang lalu drum dan takakura.

\section{b. Tingkat Keasaman (pH)}

Nilai pH dipengaruhi oleh nitrogen dari sumber bahan baku kompos (bahan organik). Nilai $\mathrm{pH}$ yang asam menunjukkan terjadi proses dekomposisi nitrogen oleh mikroorganisme menjadi ammonia, sedangkan apabila sudah menjadi ammonia nilai $\mathrm{pH}$ akan menjadi basa (Citra dkk, 2017). Menurut Suwahyono dkk (2014) nilai pH untuk kompos yang layak berada dalam rentang 5,5-9, sedangkan kompos yang ideal berada dalam rentang 6,5-8. Nilai pH menurut peraturan yang diacu yaitu SNI bahwa kompos yang dihasilkan harus berada dalam rentang 6,8-7,4. Rekapitulasi nilai pH dapat dilihat pada Tabel 3.5. 
Tabel 3.5 Nilai pH Kompos

\begin{tabular}{|c|c|c|c|c|c|c|c|c|c|c|}
\hline \multirow{2}{*}{ Komposter } & \multirow{2}{*}{ Satuan } & \multicolumn{6}{|c|}{ Nilai pH $(*)$} & \multicolumn{2}{|c|}{$\begin{array}{c}\text { Baku Mutu } \\
(* *)\end{array}$} & \multirow{2}{*}{$\begin{array}{c}\text { Kesesuaian } \\
(* * *)\end{array}$} \\
\hline & & 1 & 2 & 3 & 4 & 5 & $\begin{array}{l}\text { Rata- } \\
\text { Rata }\end{array}$ & Min & Maks & \\
\hline Bata Terawang & \multirow{3}{*}{-} & 7,05 & 7,09 & 7,15 & 7,18 & 7,19 & 7,13 & \multirow{3}{*}{6,80} & \multirow{3}{*}{7,40} & Memenuhi \\
\hline Drum & & 7,46 & 7,51 & 7,53 & 7,54 & 7,56 & 7,52 & & & Tidak Memenuhi \\
\hline Takakura & & 7,25 & 7,23 & 7,20 & 7,22 & 7,23 & 7,23 & & & Memenuhi \\
\hline
\end{tabular}

(Sumber: (*) Laboratorium Kimia Tanah UNPAD, 2018; (**) SNI 19-7030-2004; (***) Hasil Analisis Data, 2018)

Berdasarkan hasil uji laboratorium nilai rata-rata $\mathrm{pH}$ kompos yang dihasilkan oleh komposter bata terawang, drum dan takakura adalah 7,13, 7,52 dan 7,23. Apabila dibandingkan dengan SNI 19-7030-2004 kompos yang dihasilkan oleh komposter drum tidak memenuhi baku mutu, walaupun menurut literatur lain masih berada dalam rentang kompos yang layak digunakan. Menurut Dharmasetiawan (2006) bahwa semakin basa suatu nilai pH (mendekati 8) menandakan ammonia yang dihasilkan lebih besar dan akan menimbulkan bau selama proses pengomposan. Hal ini sesuai dengan keadaan saat penelitian dimana komposter drum selama proses pengomposan menghasilkan bau yang paling menyengat dibandingkan 2 komposter lainnya.

\section{c. Kadar Air}

Kadar air merupakan salah satu parameter yang harus dijaga selama proses pengomposan karena kondisi yang terlalu kering akan membuat mikroorganisme tidak berfungsi, sedangkan kondisi yang terlalu basah membuat kondisi menjadi anaerob (Hety dkk, 2017). Menurut Suwahyono dkk (2014) nilai kadar air untuk kompos yang layak berada dalam rentang 40\% - 60\%, sedangkan nilai kadar air menurut SNI 19-7030-2004 harus dibawah 50\%. Rekapitulasi nilai kadar air dapat dilihat pada Tabel 3.6.

Tabel 3.6 Nilai Kadar Air Kompos

\begin{tabular}{|c|c|c|c|c|c|}
\hline \multirow{2}{*}{ Komposter } & \multirow{2}{*}{ Satuan } & \multirow{2}{*}{ Kadar Air $(*)$} & \multicolumn{2}{|c|}{ Baku Mutu $(* *)$} & \multirow{2}{*}{$\begin{array}{c}\text { Kesesuaian } \\
(* * *)\end{array}$} \\
\hline & & & Min & Maks & \\
\hline Bata Terawang & \multirow{3}{*}{$\%$} & 44,05 & \multirow{3}{*}{-} & \multirow{3}{*}{50} & Memenuhi \\
\hline Drum & & 39,51 & & & Memenuhi \\
\hline Takakura & & 14,69 & & & Memenuhi \\
\hline
\end{tabular}

(Sumber: (*) Laboratorium Kimia Tanah UNPAD, 2018; (**) SNI 19-7030-2004; (***) Hasil Analisis Data, 2018)

Kadar air kompos yang dihasilkan oleh komposter bata terawang memiliki nilai tertinggi diikuti oleh drum dan takakura yaitu 44,05\%, 39,51\%, 14,69\%. Nilai kadar air kompos yang dihasilkan oleh ketiga komposter apabila dibandingkan dengan SNI sudah memenuhi kriteria. Kadar air dapat dipengaruhi oleh suhu, dimana panas yang timbul dari proses penguraian oleh mikroorganisme akan menguapkan air yang terkandung dalam bahan organik (Aminah dkk, 2017). Hasil penelitian sesuai dengan literatur bahwa kompos hasil komposter bata terawang memiliki nilai suhu dan kadar air tertinggi dilanjut oleh drum dan takakura. Selain itu kadar air yang kecil pada kompos hasil takakura juga dapat disebabkan oleh keberadaan bantalan sekam di dasar dan atas komposter yang dapat menyerap air. 


\section{d. Rasio C/N}

Rasio $\mathrm{C} / \mathrm{N}$ merupakan perbandingan antara karbon dan nitrogen, rasio $\mathrm{C} / \mathrm{N}$ dapat mempengaruhi kecepatan pematangan kompos. Baku mutu nilai rasio $\mathrm{C} / \mathrm{N}$ kompos yang layak untuk digunakan menurut SNI 19-7030-2004 adalah tidak boleh kurang dari 10 dan lebih dari 20. Rekapitulasi nilai rasio $\mathrm{C} / \mathrm{N}$ dapat dilihat pada Tabel 3.7.

Tabel 3.7 Nilai Rasio C/N Kompos

\begin{tabular}{|c|c|c|c|c|c|}
\hline \multirow{2}{*}{ Komposter } & \multirow{2}{*}{ Satuan } & \multirow{2}{*}{ Rasio C/N (*) } & \multicolumn{2}{|c|}{ Baku Mutu $(* *)$} & \multirow{2}{*}{$\begin{array}{c}\text { Kesesuaian } \\
(* * *)\end{array}$} \\
\hline & & & Min & Maks & \\
\hline Bata Terawang & \multirow{3}{*}{ - } & 12,4 & \multirow{3}{*}{10} & \multirow{3}{*}{20} & Memenuhi \\
\hline Drum & & 12,9 & & & Memenuhi \\
\hline Takakura & & 20,0 & & & Memenuhi \\
\hline
\end{tabular}

(Sumber: (*) Laboratorium Kimia Tanah UNPAD, 2018; (**) SNI 19-7030-2004; (***) Hasil Analisis Data, 2018)

Berdasarkan hasil uji laboratorium menunjukkan bahwa kompos dengan rasio $\mathrm{C} / \mathrm{N}$ tertinggi berasal dari komposter takakura yang diikuti oleh drum dan bata terawang. Selain itu, nilai rasio C/N kompos hasil ketiga komposter memenuhi baku mutu. Menurut Mulyono (2014) rasio $\mathrm{C} / \mathrm{N}$ yang terlalu tinggi menandakan mikroorganisme pengurai tidak optimal berkembang karena kekurangan nitrogen, sedangkan rasio $\mathrm{C} / \mathrm{N}$ yang terlalu rendah menandakan banyaknya kehilangan nitrogen dalam bentuk ammonia. Nilai rasio $\mathrm{C} / \mathrm{N}$ kompos hasil takakura tertinggi menunjukkan pengomposan dengan takakura berpotensi lebih cepat matang dibandingkan menggunakan 2 jenis komposter lainnya. Selain itu, nilai rasio $\mathrm{C} / \mathrm{N}$ yang tinggi juga menunjukkan bahwa perbandingan antara kadar nitrogen dan kadar organik pada kompos hasil takakura jauh lebih besar dibandingkan kompos lainnya.

\section{e. Unsur Hara Mikro}

Dilakukan pengukuran kandungan unsur hara mikro dalam kompos. Hal ini bertujuan sebagai nilai tambah kompos dalam memenuhi kebutuhan untuk pertumbuhan tanaman. Parameter unsur hara mikro yang diuji adalah tembaga (Cu) dan seng ( $\mathrm{Zn}$ ). Menurut Mulyono (2014) unsur tembaga dibutuhkan oleh tumbuhan khususnya untuk keperluan fotosintesis, sedangkan unsur seng dibutuhkan untuk membantu proses fotosintesis. Baku mutu menurut SNI 19-7030-2004 batasan maksimum kandungan unsur tembaga pada kompos adalah 100 $\mathrm{mg} / \mathrm{kg}$ dan unsur seng $500 \mathrm{mg} / \mathrm{kg}$. Rekapitulasi nilai unsur hara mikro dapat dilihat pada Tabel 3.8 .

Tabel 3.8 Nilai Unsur Hara Mikro Kompos

\begin{tabular}{|c|c|c|c|c|c|c|c|c|c|}
\hline \multirow{3}{*}{ Komposter } & \multirow{3}{*}{ Satuan } & \multicolumn{2}{|c|}{ Nilai Unsur $(*)$} & \multicolumn{4}{|c|}{ Baku Mutu $(* *)$} & \multicolumn{2}{|c|}{ Kesesuaian $(* * *)$} \\
\hline & & \multirow{2}{*}{ Tembaga } & \multirow{2}{*}{ Seng } & \multicolumn{2}{|c|}{ Tembaga } & \multicolumn{2}{|c|}{ Seng } & \multirow{2}{*}{ Tembaga } & \multirow{2}{*}{ Seng } \\
\hline & & & & Min & Maks & Min & Maks & & \\
\hline Bata Terawang & \multirow{3}{*}{$\mathrm{mg} / \mathrm{kg}$} & 33,72 & 73,42 & \multirow{3}{*}{-} & \multirow{3}{*}{100} & \multirow{3}{*}{-} & \multirow{3}{*}{500} & Memenuhi & Memenuhi \\
\hline Drum & & 35,62 & 82,64 & & & & & Memenuhi & Memenuhi \\
\hline Takakura & & 34,93 & 63,98 & & & & & Memenuhi & Memenuhi \\
\hline
\end{tabular}

Hasil pengukuran menunjukkan bahwa unsur hara mikro tertinggi dihasilkan oleh komposter drum. Sumber unsur hara mikro pada kompos berasal dari kontaminasi air lindi yang dihasilkan (Fatmawinir dkk, 2015). Hal ini sesuai dengan kondisi penelitian bahwa air lindi yang dihasilkan oleh komposter drum lebih banyak akibat komposter drum terbuat dari 
plastik yang tidak memiliki banyak rongga dibandingkan komposter lainnya. Unsur tembaga dan seng yang dapat diserap oleh tanaman dalam bentuk $\mathrm{Cu}^{2+}$ dan $\mathrm{Zn}^{2+}$ melalui akar.

\subsection{Rekapitulasi Perbandingan Komposter}

Efektifitas masing-masing komposter dapat dilihat dari perbandingan beberapa kriteria hasil penelitian. Rekapitulasi perbandingan komposter dilihat pada Tabel 3.9.

\section{Tabel 3.9 Rekapitulasi Perbandingan Komposter}

\begin{tabular}{|c|c|c|c|c|c|c|c|}
\hline \multirow{3}{*}{ Komposter } & \multicolumn{6}{|c|}{ Kriteria } & \\
\hline & \multirow{2}{*}{$\begin{array}{c}\text { Kapasitas } \\
\text { Komposter } \\
(*)\end{array}$} & \multirow{2}{*}{$\begin{array}{c}\text { Kinerja } \\
\text { Komposter } \\
(*)\end{array}$} & \multicolumn{5}{|c|}{ Kualitas Kompos $(* *)$} \\
\hline & & & Suhu & $\mathbf{p H}$ & $\begin{array}{l}\text { Kadar } \\
\text { Air }\end{array}$ & $\begin{array}{c}\text { Rasio } \\
\text { C/N }\end{array}$ & $\begin{array}{l}\text { Unsur Hara } \\
\text { Mikro }\end{array}$ \\
\hline $\begin{array}{c}\text { Bata } \\
\text { Terawang }\end{array}$ & 456 sumber & $53,45 \%$ & \multirow{3}{*}{$\begin{array}{c}\text { Memenuhi } \\
\text { Baku } \\
\text { Mutu }\end{array}$} & $\begin{array}{l}\text { Memenuhi } \\
\text { Baku Mutu }\end{array}$ & \multirow{3}{*}{$\begin{array}{c}\text { Memenuhi } \\
\text { Baku } \\
\text { Mutu }\end{array}$} & \multirow{3}{*}{$\begin{array}{c}\text { Memenuhi } \\
\text { Baku } \\
\text { Mutu }\end{array}$} & \multirow{3}{*}{$\begin{array}{l}\text { Memenuhi } \\
\text { Baku Mutu }\end{array}$} \\
\hline Drum & 210 sumber & $48,27 \%$ & & $\begin{array}{c}\text { Tidak } \\
\text { Memenuhi } \\
\text { Baku Mutu }\end{array}$ & & & \\
\hline Takakura & 20 sumber & $56,01 \%$ & & $\begin{array}{l}\text { Memenuhi } \\
\text { Baku Mutu }\end{array}$ & & & \\
\hline
\end{tabular}

(Sumber: (*) Hasil Perhitungan, 2018; (**) Laboratorium Kimia Tanah UNPAD, 2018)

Berdasarkan Tabel 3.9 menunjukkan komposter yang dapat menampung sampah dari sumber dengan jumlah yang relatif banyak (komunal) adalah bata terawang dan drum, sedangkan takakura dapat menampung sampah dengan jumlah yang relatif sedikit (individual). Hasil penelitian menunjukkan bahwa komposter takakura memiliki kinerja paling baik yang diikuti oleh bata terawang dan drum. Rata-rata kinerja komposter yang tersedia di Bank sampah Sahdu sebesar 50\%. Hal ini menunjukkan bahwa kinerja komposter sudah cukup efektif dalam mengolah sampah organik menjadi kompos yang layak digunakan.

Kualitas kompos yang dihasilkan dari masing-masing komposter secara garis besar sudah memenuhi baku mutu yaitu SNI 19-7030-2004. Nilai pH kompos hasil komposter drum tidak memenuhi baku mutu, walaupun menurut literatur lain masih dalam batas normal. Hal ini menunjukkan bahwa komposter bata terawang, drum dan takakura dapat menghasilkan kompos yang layak digunakan.

\section{KESIMPULAN}

Efektifitas komposter yang tersedia di Bank sampah Sahdu ditinjau dari kapasitas komposter, kinerja komposter dan kualitas kompos. Berdasarkan hasil pengukuran menunjukkan kapasitas komposter terbesar adalah bata terawang yang dapat menampung sampah dari 456 sumber, sedangkan kapasitas drum dan takakura adalah dari 210 sumber dan 20 sumber. Kinerja komposter dalam mengolah sampah organik dilihat dari persentase kompos halus yang dihasilkan. Kinerja komposter terbesar adalah takakura dilanjut dengan bata terawang dan drum yaitu 56,01\%, 53,45\% dan 48,27\%. Parameter kualitas kompos yang diuji dan diukur antara lain suhu, $\mathrm{pH}$, kadar air, rasio $\mathrm{C} / \mathrm{N}$ dan unsur hara mikro. Suhu kompos tertinggi hasil komposter bata terawang selanjutnya drum dan takakura yaitu $29^{\circ} \mathrm{C}$, $27^{\circ} \mathrm{C}$ dan $24^{\circ} \mathrm{C}$. Rata-rata $\mathrm{pH}$ kompos tertinggi hasil komposter drum selanjutnya takakura dan bata terawang yaitu 7.52, 7,23 dan 7,13. Kadar air kompos tertinggi yaitu bata terawang dilanjut drum dan takakura yaitu 44,05\%, 39,51\%, 14,69\%. Rasio C/N kompos tertinggi hasil komposter takakura selanjutnya drum dan bata terawang yaitu 20,12,9, 12,4. Ditinjau dari kandungan unsur hara mikro yaitu tembaga $(\mathrm{Cu})$ dan seng $(\mathrm{Zn})$, kompos hasil komposter drum memiliki nilai tertinggi dibandingkan 2 kompos lainnya. Kualitas kompos 
yang dihasilkan oleh seluruh komposter sudah memenuhi baku mutu, kecuali parameter $\mathrm{pH}$ kompos hasil komposter drum yang tidak memenuhi baku mutu.

\section{DAFTAR RUJUKAN}

Aminah, S., Sudarno., Purwono. (2017). Pengaruh Aerasi Terhadap Karakteristik Lindi Hasil Pengolahan Sampah Organik Secara Biodrying Studi Kasus: Sayuran Kangkung. Jurnal Teknik Lingkungan, 2017.

Badan Standarisasi Nasional. Spesifikasi Kompos dari Sampah Organik Domestik. SK SNI 197030-2004.

Citra, V., Sumiyati, S., Samudro, G., (2017). Pengaruh Kadar Air Terhadap Hasil Pengomposan Sampah dengan Metode Open Windrow. Jurnal Teknik Mesin, 2017.

Dharmasetiawan, Martin. (2006). Daur Ulang Sampah dan Pembuatan Kompos. Jakarta: Ekamitra.

Fatmawinir., Suyani, H., Alif, A. (2015). Analisis Sebaran Logam Berat Pada Aliran Air Dari Tempat Pembuangan Akhir (TPA) Sampah Air Dingin. ISSN : 1978-628X.

Hety, Yovita., Praseya, B. (2017). Cara Mudah dan Cepat Buat Kompos. Jakarta: Penebar Swadaya.

Kementerian Lingkungan Hidup dan Kehutanan Republik Indonesia. (2017). IndonesiaFinlandia Bahas Kerjasama Pengelolaan Sampah Menjadi Energi. Tersedia di: http://www.menlhk.go.id/berita-189-indonesia--finlandia-bahas-kerjasama-pengelolaansampah-menjadi-energi.html. Diakses 17 Februari 2018.

Kementerian Lingkungan Hidup dan Kehutanan Republik Indonesia. (2018). Pengelolaan Sampah dan Perubahan Iklim. Jakarta: Kementerian Lingkungan Hidup dan Kehutanan.

Mulyono. (2014). Membuat MOL dan Kompos dari Sampah Rumah Tangga. Jakarta: PT. Agro Media Pustaka.

Presiden Republik Indonesia. (2008). Undang-Undang Republik Indonesia Nomor 18 Tahun 2008 tentang Pengelolaan Sampah. Jakarta: Sekretariat Negara.

Soma, Soekmana. (2010). Pengantar Ilmu Teknik Lingkungan. Bogor: IPB Press.

Sugiyono. (2009). Metode Penelitian Kuantitatif Kualitatif dan R\&D. Bandung: Alfabeta.

Suwahyono, Untung., dkk. (2014). Cara Cepat Buat Kompos dari Limbah. Jakarta: Penebar Swadaya.

Yulianto, A., dkk. (2009). Pengolahan Sampah Terpadu: Konversi Sampah Pasar Menjadi Kompos Berkualitas Tinggi. Jakarta: Yayasan Danamon Peduli.

Tchobanoglous, G., et al. (1993). Integrated Solid Waste Management: Engineering Principles and Management Issues. McGraw-Hill Inc. 